Fitofarmaka, Vol 3, No. 2, Desember 2013 ISSN: 2087-9164

\title{
ANALISIS FARMAKOEKONOMI SIMPLISIA UNTUK HIPERTENSI DALAM SAINTIFIKASI JAMU
}

\author{
Imas Maesaroh, Supriyatna, Hadiyana Sukandar Program \\ Magister Ilmu Farmasi Konsentrasi Herbal Medik Fakultas \\ Farmasi Universitas Padjadjaran
}

\begin{abstract}
ABSTRAK
Penelitian ini dirancang untuk mengetahui efektivitas biaya pada pasien hipertensi yang menggunakan simplisia jamu hipertensi yang selanjutnya dinamakan jamu hipertensi SJ, dibandingkandenganobat konvensional (obat generik) antihipertensi dan kombinasi keduanya. Data diambil secara retrospektif dari bulan Januari-Desember 2013. Analisis efektivitas biaya dilakukan dengan perspektif ASKES. Komponen biaya yang diukur adalah biaya medik langsung, mencakup biaya obat antihipertensi, biaya pemeriksaan medis dan biaya pendaftaran. Efektivitas terapi yang diukur adalah penurunan tekanan darah. Average cost effectivenes ratio (ACER) dihitung berdasarkan rasio biaya dan efektivitas terapi pada kedua kelompok terapi. Incremental cost effectivenes ratio (ICER) dihitung berdasarkan rasio antara selisih biaya dan efektivitas terapi pada kedua kelompok terapi. Kelompok terapi yang mempunyai nilai ACER dan ICER lebih rendah menunjukkan lebih costeffective. Berdasarkan parameter efektivitas terapi berupa \% penurunan tekanan darah, nilai ACER pada kelompok jamu hipertensi SJ, captopril 25, kombinasi jamu hipertensi SJ + amlodipin, dan amlodipinberurutan adalahRp 670,17; Rp 707,39; Rp 1.155,39dan Rp 1.163,27. Berdasarkan hasil penelitian dapat disimpulkan bahwa jamu hipertensi SJ lebih cost effectivedibandingkan obat generik captopril 25,amlodipin dan kombinasi jamu antihipertensi + amlodipindalam menurunkan tekanan darah. Nilai ICER menunjukkan bahwa terapi jamu hipertensi SJdan kombinasi jamu hipertensi SJ + amlodipin perlu penambahan biaya sebesar $\mathrm{Rp} 554,35$ dan $\mathrm{Rp} 1.121,32$; untuk setiap $1 \%$ penurunan tekanan darah dibandingkan dengan captopril 25 dan amlodipin.
\end{abstract}

Kata kunci: Saintifikasi jamu, simplisia, antihipertensi,captopril, amlodipine, efektivitas biaya

\begin{abstract}
This study was designed to determine costeffective on the patients of hypertensive that used crude drugs of jamu scientificationfor hypertension, antihypertensive conventional drugs(generic drugs)and combination of both. The data was taken from January - December 2013 retrospectively. Costeffectiveanalysis was conducted by AKSES perspective. Component of cost was measured is direct medical cost, covered the drug of hypertensive cost, medical examination cost, and registrations cost. The effectiveness of therapy that measured is the decreasing of blood pressure. Average costeffectiveness ratio (ACER) calculated based on the cost ratio and therapy effectiveness inboth treatment groups. Incremental costeffectiveness ratio (ICER) was calculated based on the ratio between the deviation in costandeffectiveness ofthetwo treatment groups. The group of therapy that has lower ACER and ICER value indicated more cost-effective. Based on parameter of therapy effectiveness in the form \% decreasing of blood pressure, the value of ACER on
\end{abstract}


groups ofjamu scientificiation forhypertensive, captopril 25 , combination of jamu scientification for hypertensive + amlodipin and amlodipin in sequent are Rp 670,17; Rp 707,39 ; Rp 1.155,39 and Rp. 1.163,27. Based on the result of the study concluded that jamu scientificiation for hypertensivemore cost-effective than generic drugs captopril 25, amlodipin and combination of jamu scientification for hypertensive + amlodipin in decreasing blood pressure. The value of ICER showed that jamu scientification for hypertensive therapy and combination of jamu scientification for hypertensive + amlodipin need additional cost at $\mathrm{Rp} 554,35$ and $\mathrm{Rp} 1.121,32$; for every $1 \%$ of decreasing blood pressure compared with captopril 25 and amlodipin.

Keywords: Jamu scientification, crude durgs, antihypertensive, cost effectiveness

\section{PENDAHULUAN}

Hipertensi termasuk penyakit metabolik yaitu gangguan fungsi metabolisme tubuh akibat konsumsi berbagai jenis makanan yang tidak terkendali. Untuk menanggulangi penyakittersebut diperlukan pemakaian obat dalam waktu lama sehingga jika digunakan obat modern (obat konvensional) dikhawatirkan adanya efek samping yang terakumulasi terus menerus dan dapat merugikan kesehatan. Oleh karena itu lebih sesuai bila menggunakan obat alam / obat tradisional, walaupun penggunaanya dalam waktu lama tetapi efek sampingnya relatif kecil (jika digunakan secara tepat dan rasional) sehingga dianggap lebih aman (Katno, 2008).

Jamu sudah dikenal sejak dahulu sebagai obat herbal Indonesia. Riset Kesehatan Dasar pada tahun 2010 menunjukkan bahwa penduduk Indonesia yang mengkonsumsi jamu sebesar 95,60\% pernah merasakan manfaatnya pada semua kelompok umur dan status ekonomi, baik di pedesaan maupun diperkotaan tetapi pemanfaatannya selama ini masih sebatas pengobatan sendiri dan belum dilakukan di fasilitas kesehatan (Balitbangkes, 2010).

Mengacukepada Peraturan Menteri Kesehatan Republik Indonesia Nomor 1109/Menkes/Per/IX/2007 tentang penyelenggaraan pengobatan komplementer alternative di fasilitas kesehatan, Kementerian Kesehatan RI telah mencanangkan program unggulan
Saintifikasi Jamu pada tahun 2010 di Kabupaten Kendal Jawa Tengah kemudian diatur melalui Permenkes RI Nomor 003/Menkes/Per/2010 tentang saintifikasi jamu dalam penelitian berbasis pelayanan kesehatan (Kemenkes RI, 2007 dan Kemenkes RI, 2010).

$$
\text { Program saintifikasi jamu }
$$

dikembangkan agar jamu dapat dipromosikan oleh profesional medis dalam kesehatan formal. Program ini bertujuan untuk memberikan dasar ilmiah pemanfaatan jamu di pelayanan kesehatan, membangun jaringan, mendorong penyediaan jamu yang aman, efektif, dan berkualitas untuk pemanfaatan di pelayanan kesehatan.

Langkah pertama saintifikasi jamu, difokuskan pada empat formula dengan indikasi untuk mengatasi gejala hipertensi, hiperglikemia, hiperurisemia dan hiperkolesterol. Dari empat formula jamu yang diteliti, dua formula sudah ada bukti ilmiahnya, yakni jamu tekanan darah tinggi dan asam urat. Dua jenis jamu itu mendapat sertifikat dari Komisi Nasional Saintifikasi Jamu serta dinyatakan terbukti aman dan berkhasiat. Penelitian meliputi uji standarisasi, toksisitas pada hewan coba, observasiklinik, dan uji klinik. Komposisi jamu tekanan darah tinggi adalah seledri, daun kumis kucing, daun pegagan, rimpang temulawak, rimpang kunyit, dan meniran. Seledri, daun kumis kucing, dan daun pegagan merupakan bahan berkhasiat sebagai antihipertensi Matsubara, et al., 1999, Li-ming, et 
al.2010, Siska, dkk.2011, Galicia, et al., 2013, Intharacton and Srisaawat, 2013)., Sedangkan rimpang temulawak, kunyit dan meniran merupakan bahan penyegar. Tetapi dari hasil penelitian, temulawak merupakan hepatoprotektor (Chowli, et al., 1995) dan meniran sebagai hepatoprotektor dan immunodilator (Ting, et al., 2006, Zalizar, 2013). Penggunaan jamu yang sudah disaintifikasi terbukti aman dan berkhasiat perlu diikuti dengan kajian bagaimana biaya dan efektivitas saintifikasi jamu secara farmakoekonomi untuk pengobatan hipertensi dibandingkan dengan obat konvensional (obat generik) yang relatif murah, sehingga saintifikasi jamu dapat dirasakan manfaatnya oleh seluruh masyarakat. Dari literatur disebutkan bahwa penggunaan tanaman obat menawarkan berbagai keuntungan, yaitu relatif aman, sedikitnya efek samping, dan pada umumnya biaya yang lebih rendah (harga yang lebih murah) dibandingkan dengan biaya untuk pengobatan konvensional (Supriyatna, dkk., 2013).

\section{METODOLOGI PENELITIAN}

Penelitian ini menggunakan metode non eksperimental dengan pengambilan data secara retrospektif untuk menilai efektivitas biaya pengobatan hipertensi dengan terapi simplisia saintifikasi jamu hipertensi yang selanjutnya dinamakan jamu hipertensi SJ, obat konvensional (obat generik) antihipertensi dan kombinasi keduanya.

Populasi adalah data rekam medik semua pasien hipertensi yang berobat jalan ke Puskesmas Gondomanan Yogyakarta pada bulan JanuariDesember 2013. Kriteria inklusi pasien: pasien yang terdiagnosis hipertensi yang berusia 18 tahun atau lebih, data rekam medik pasien hipertensi dengan tekanan darah > 120/80 $\mathrm{mmHg}$, pasien yang diberi jamuhipertensi SJ dan obat generik antihipertensi. Kriteria eksklusi: pasien dengan penyakit penyerta, pasien yang mengalami gangguan fungsi ginjal dan fungsi hati, data status pasien

Analisis efektivitas yang tidak lengkap, hilang dan tidak jelas terbaca. biaya dilakukan dengan perspektif ASKES. Komponen biaya yang diukur adalah biaya medik langsung, mencakup biaya obat hipertensi, biaya pemeriksaan medis dan biaya pendaftaran kunjungan ke puskesmas. Efektivitas terapi yang diukur adalah penurunan tekanan darah. Efektivitas terapi dianalisis menggunakan paired sample $t$ test. Average cost effectiveness ratio (ACER) dihitung berdasarkan rasio biaya dan efektivitas terapi pada kelompok jamu hipertensi SJ, obat generik antihipertensi dan kombinasi keduanya. Incremental cost effectiveness ratio (ICER) dihitung berdasarkan rasio antara selisih biaya dan efektivitas terapi pada kedua kelompok terapi.

\section{HASIL DAN PEMBAHASAN \\ Karakteristik pasien}

Pasien hipertensi rawat jalan yang menggunakan jamu hipertensi SJ di puskesmas Gondomanan Yogyakarta pada bulan januari-Desember 2013 yang memenuhi kriteria inklusi berjumlah 9 orang dan semuanya adalah perempuan, frekuensi pengobatan sebanyak 21 kali. Mayoritas pasien pengguna saintifikasi jamu antihipertensi adalah pasien dengan kelompok usia 54 - 65 tahun 8 orang ( $88,89 \%$ )sedangkan pasien dengan kelompok usia > 65 tahun (lanjut usia) 1 orang $(11,11 \%)$. Pasien tersebut sebelum dan sesudah diberikan terapi diukur tekanan darah sistolik/diastoliknya, kemudian diberikan terapi dengan jamu hipertensi SJ, obat generik captopril 25, amlodipin dan kombinasi jamu hipertensi SJ+amlodipin tergantung pada kondisi pasien (Tabel 1) 
Fitofarmaka, Vol 3, No. 2, Desember 2013 ISSN: 2087-9164

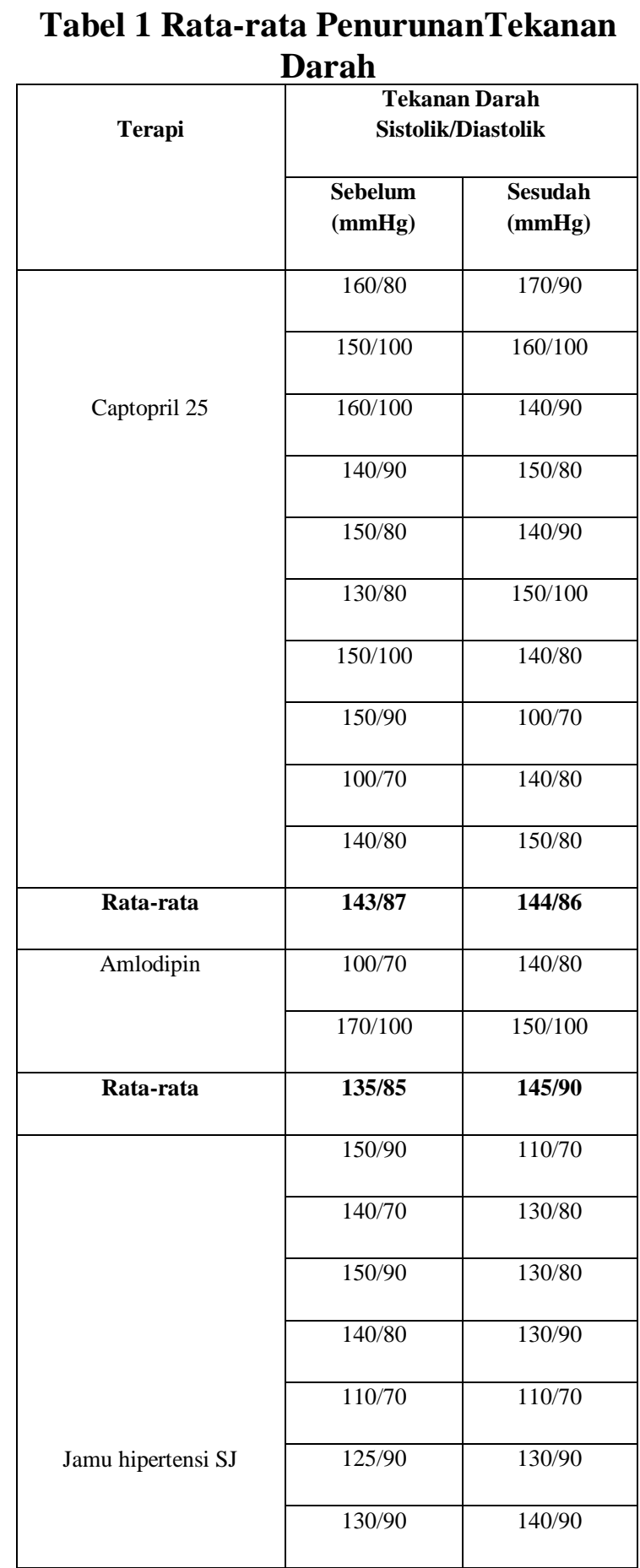

Dari data percobaan terlihat bahwa pasien yang diberikan jamu hipertensi SJ adalah pasien hipertensi yang mempunyai tekanan darah $110-160$ $\mathrm{mmHg}$.

\section{Efektivitas terapi antihipertensi} berdasarkan tekanan darah

\begin{tabular}{|c|c|c|}
\hline & $140 / 90$ & $165 / 100$ \\
\hline & $140 / 90$ & $130 / 90$ \\
\hline & $130 / 90$ & $150 / 100$ \\
\hline & $130 / 90$ & $110 / 70$ \\
\hline & $110 / 70$ & $130 / 80$ \\
\hline & $150 / 100$ & $130 / 80$ \\
\hline & $140 / 80$ & $120 / 80$ \\
\hline & $120 / 80$ & $110 / 70$ \\
\hline & $150 / 80$ & $140 / 90$ \\
\hline & $160 / 110$ & $160 / 95$ \\
\hline & $150 / 100$ & $130 / 90$ \\
\hline & $130 / 80$ & $130 / 80$ \\
\hline & $130 / 80$ & $120 / 80$ \\
\hline & $120 / 80$ & $150 / 80$ \\
\hline Rata-rata & $150 / 86$ & 131/84 \\
\hline \multirow{10}{*}{$\begin{array}{c}\text { Jamu hipertensi } \\
\text { SJ+Amlodipin }\end{array}$} & $140 / 70$ & $100 / 70$ \\
\hline & $100 / 70$ & $120 / 80$ \\
\hline & $120 / 80$ & $140 / 80$ \\
\hline & $140 / 80$ & $130 / 85$ \\
\hline & $130 / 85$ & $150 / 80$ \\
\hline & $150 / 80$ & $160 / 90$ \\
\hline & $160 / 90$ & $150 / 90$ \\
\hline & $130 / 80$ & $125 / 80$ \\
\hline & $150 / 80$ & $110 / 80$ \\
\hline & $110 / 80$ & $135 / 80$ \\
\hline Rata-rata & 133/80 & $132 / 82$ \\
\hline
\end{tabular}

tekanan darah rata-rata pada tabel 1 , terapi dengan jamu hipertensi SJ mampu menurunkan tekanan darah rata-rata $12,67 \%$. Terapi dengan captopril 25 tekanan darah rata-rata meningkat sebesar 0,70\%. Terapi dengan amlodipin tekanan darah rata-rata meningkat sebesar 7,41 \% dan terapi dengan 
kombinasi jamu hipertensi SJ+amlodipin tekanan darah rata-rata menurun sebesar $0,75 \%$.

\section{Biaya Terapi}

Biaya terapi mencakup biaya obat hipertensi, biaya pemeriksaan medis dan biaya pendaftaran kunjungan ke puskesmas. Biaya obat mencakup seluruh obat yang diresepkan untuk mengatasi hipertensi. Biaya obat generik lebih rendah dibandingkan dengan saintifikasi jamu untuk pengobatan hipertensi.

Biaya pendaftaran dan biaya pemeriksaan merupakan komponen biaya medik langsung sesuai standar puskesmas Gondomanan Yogyakarta. Biaya pendaftaran rata-rata Rp 5.000,00 dan untuk pasien lanjut usiasebesar $\mathrm{Rp}$ 2.000,00 sedangkan biaya pemeriksaan rata-rata $\mathrm{Rp} 7.000,00$ dan untuk pasien lanjut usia sebesar Rp 3.500,00.

Biaya total terapi adalah seluruh biaya medik langsung rata-rata per minggu yang dikeluarkan selama menjalani terapi, yaitu merupakan penjumlahan dari komponen biaya obat, pemeriksaan medis dan biaya pendaftaran.

\section{Efektivitas Biaya Terapi}

Efektifitas dibagi menjadi 2 kategori yaitu kategori efektif dan tidak efektif. Kategori efektif adalah terapi yang mengalami penurunan tekanan darah sistolik sedangkan kategori tidak efektif adalah yang tidak mengalami penurunan tekanan darah sistolik.

Average Cost EffectivenessRatio (ACER) adalah metoda yang dikembangkan oleh ahli-ahli ekonomi yang dalam ilmu kesehatan berguna untuk mencari suatu terapi yang paling efektif baik dari segi biaya maupun efektifitasnya. Hasil perhitungan dimanfaatkan untuk membantu memilih beberapa intervensi kesehatan masyarakat (Mukti, 2000). Untuk memperjelas hasil penelitian maka dilakukan perhitungan Incremental Cost
Effectiveness ratio (ICER). ICER dapat digunakan untuk mendeterminasi biaya tambahan dan peningkatan efektifitas antara beberapa terapi. Jika biaya tambahan ini rendah, berarti obat tersebut dapat dipilih, sebaliknya jika biaya tambahan sangat tinggi maka obat tersebut tidak baik untuk dipilih [15;16]

Data hasil evaluasi efektifitas terapi hipertensi dapat dilihat pada tabel 2.

Harga ACER diperoleh dari rasio antara biaya total terapi rata-rata per minggu dan efektivitas terapi. Efektivitas terapi yang diukur adalah \% penurunan tekanan darah. Harga ICER diperoleh dari rasio antara selisih biaya total terapi dan $\%$ penurunan tekanan darah pada masing-masing terapi.

Berdasarkan parameter efektivitas terapi (Tabel 3 dan 4) berupa \% penurunan tekanan darah, nilai ACER pada kelompok jamu hipertensi SJ lebih kecil dibandingkan dengan amlodipin, captopril 25 dan kombinasi amlodipinjamu hipertensi SJ. Oleh karena itu, terapi jamu hipertensi SJ lebih costeffective dibandingkan amlodipin, captopril 25 dan kombinasi jamu hipertensi SJ+amlodipin dalam menurunkan tekanan darah tetapi nilai ICER menunjukkan bahwa terapi jamu hipertensi SJ membutuhkan penambahan biaya sebesar Rp 554,35 untuk setiap 1\% penurunan tekanan darah dibandingkan dengan terapi captopril 25. Sedangkan nilai

ACER pada kelompok kombinasi jamu hipertensi SJ+amlodipin lebih kecil dibandingkan dengan amlodipin. Oleh karena itu, terapi kombinasi jamu hipertensi+amlodipin lebih cost-effective dibandingkan dengan amlodipin dalam menurunkan tekanan darah. Nilai ICER kombinasi jamu hipertensi SJ+amlodipin membutuhkan penambahan biaya sebesar Rp 1.121,32 untuk setiap 1\% penurunan tekanan darah dibandingkan dengan amlodipin. 
Fitofarmaka, Vol 3, No. 2, Desember 2013 ISSN: 2087-9164

Tabel 2. Distribusi Hasil Efektifitas Pengunaan Obat Hipertensi

\begin{tabular}{|c|c|c|c|c|c|c|c|c|}
\hline \multirow[t]{2}{*}{ Evaluasi Efektivitas } & \multicolumn{2}{|c|}{\begin{tabular}{|c|} 
Jamu \\
hipertensi SJ \\
\end{tabular}} & \multicolumn{2}{|c|}{ Amlodipin } & \multicolumn{2}{|c|}{$\begin{array}{l}\text { Jamu hipertensi } \\
\text { SJ+Amlodipin }\end{array}$} & \multicolumn{2}{|c|}{ Captopril 25} \\
\hline & \multicolumn{4}{|c|}{ sebelum sesudahsebelum sesudah } & Sebelum & Sesudah & sebelum & sesudah \\
\hline $\begin{array}{lll}\begin{array}{l}\text { Penurunan } \\
(\mathrm{mmHg})\end{array} & \text { tekanan } & \text { darah } \\
\end{array}$ & 141 & 113 & 170 & 150 & 144 & 123 & 153 & 130 \\
\hline \% Efektivitas & \multicolumn{2}{|c|}{19,86} & \multicolumn{2}{|c|}{11,76} & \multicolumn{2}{|c|}{14,48} & \multicolumn{2}{|c|}{15,03} \\
\hline
\end{tabular}

Tabel 3. Biaya Total TerapiAntihipertensi

\begin{tabular}{|c|c|c|c|c|c|c|c|c|}
\hline $\begin{array}{c}\text { Komponen } \\
\text { Biaya }\end{array}$ & $\begin{array}{c}\text { Kel. Jamu } \\
\text { hipertensi SJ } \\
\text { Jumlah (Rp) }\end{array}$ & $(\%)$ & $\begin{array}{c}\text { Kel. } \\
\text { Amlodipin } \\
\text { Jumlah } \\
\text { (Rp) }\end{array}$ & $(\%)$ & $\begin{array}{c}\text { Jamu hipertensi } \\
\text { SJ + Kel. } \\
\text { Amlodipin } \\
\text { Jumlah } \\
\text { (Rp) }\end{array}$ & $(\%)$ & $\begin{array}{c}\text { Kel. } \\
\text { Captopril } 25 \\
\text { Jumlah } \\
\text { (Rp) }\end{array}$ & $(\%)$ \\
\hline $\begin{array}{l}\text { Biaya } \\
\text { Antihipertensi }\end{array}$ & $5.000,00$ & 37,6 & $1.680,00$ & 12,28 & $6.680,00$ & 39,93 & $1.232,00$ & 11,59 \\
\hline $\begin{array}{l}\text { Biaya } \\
\text { Pemeriksaan }\end{array}$ & $5.166,67$ & 38,8 & $7.000,00$ & 51,17 & $5.950,00$ & 35,56 & $5.600,00$ & 52,67 \\
\hline $\begin{array}{l}\text { Biaya } \\
\text { Pendaftaran }\end{array}$ & $3.142,86$ & 23,6 & $5.000,00$ & 36,55 & $4.100,00$ & 24,51 & $3.800,00$ & 35,74 \\
\hline $\begin{array}{l}\text { Biaya Total } \\
\text { Terapi }\end{array}$ & $13.309,53$ & 100 & $13.680,00$ & 100 & $16.730,00$ & 100 & $10.632,00$ & 100 \\
\hline
\end{tabular}


Fitofarmaka, Vol 3, No. 2, Desember 2013 ISSN: 2087-9164

Tabel 4. Efektivitas Biaya Terapi Antihipertensi

\begin{tabular}{|c|c|c|c|}
\hline Parameter & & Jamu hipertensi SJ & Amlodipin \\
\hline Biaya total terapi & & Rp 13.309,53 & Rp 13.680,00 \\
\hline \multirow{3}{*}{$\begin{array}{l}\text { Efektivitas terapi } \\
\text { berdasarkan tekanan } \\
\text { darah }\end{array}$} & $\begin{array}{l}\text { \% Penurunan } \\
\text { tekanan darah }\end{array}$ & $19,86 \%$ & $11,76 \%$ \\
\hline & ACER & $\operatorname{Rp} 670,17$ & Rp $1.163,27$ \\
\hline & ICER & & $\mathrm{Rp}-45,74$ \\
\hline Parameter & & $\begin{array}{c}\text { Jamu hipertensi SJ+ } \\
\text { Amlodipin }\end{array}$ & Amlodipin \\
\hline Biaya total terapi & & $\operatorname{Rp} 16.730,00$ & Rp 13.680,00 \\
\hline \multirow{3}{*}{$\begin{array}{l}\text { Efektivitas terapi } \\
\text { berdasarkan tekanan } \\
\text { darah }\end{array}$} & $\begin{array}{l}\text { \% Penurunan } \\
\text { tekanan darah }\end{array}$ & $14,48 \%$ & $11,76 \%$ \\
\hline & ACER & Rp 1.155,39 & $\operatorname{Rp} 1.163,27$ \\
\hline & ICER & & $\operatorname{Rp} 1.121,32$ \\
\hline Parameter & & Jamu hipertensi SJ & Captopril 25 \\
\hline Biaya total terapi & & Rp 13.309,53 & Rp 10.632,00 \\
\hline \multirow{3}{*}{$\begin{array}{l}\text { Efektivitas terapi } \\
\text { berdasarkan tekanan } \\
\text { darah }\end{array}$} & $\begin{array}{l}\text { \% Penurunan } \\
\text { tekanan darah }\end{array}$ & $19,86 \%$ & $15,03 \%$ \\
\hline & ACER & $\operatorname{Rp} 670,17$ & $\operatorname{Rp} 707,39$ \\
\hline & ICER & & $\operatorname{Rp} 554,35$ \\
\hline Parameter & & Jamu hipertensi SJ & $\begin{array}{c}\text { Jamu hipertensi SJ+ } \\
\text { Amlodipin }\end{array}$ \\
\hline Biaya total terapi & & Rp 13.309,53 & Rp 16.730,00 \\
\hline \multirow{3}{*}{$\begin{array}{l}\text { Efektivitas terapi } \\
\text { berdasarkan tekanan } \\
\text { darah }\end{array}$} & $\begin{array}{l}\text { \% Penurunan } \\
\text { tekanan darah }\end{array}$ & $19,86 \%$ & $14,48 \%$ \\
\hline & ACER & $\operatorname{Rp} 670,17$ & Rp 1.155,39 \\
\hline & ICER & & Rp $-635,77$ \\
\hline
\end{tabular}

\section{Kesimpulan}

Berdasarkan hasil penelitian dapat disimpulkan bahwa jamu hipertensi SJ lebih cost-effective dibandingkan, captopril 25, kombinasi jamu hipertensi SJ+amlodipin dan amlodipin dalam menurunkan tekanan darah. Nilai ICER menunjukkan bahwa terapi jamu hipertensi SJ dan kombinasi jamu hipertensi SJ+amlodipin membutuhkan penambahan biaya berurutan sebesar Rp
554,35 dan Rp 1.121,32 untuk setiap 1\% penurunan tekanan darah dibandingkan dengan captopril 25 dan amlodipin.

\section{DAFTAR PUSTAKA}

Balitbangkes, 2010, Riset Kesehatan Dasar (Riskesdas) 2010, Badan Litbang Kesehatan, Jakarta

Chowli S, Ching Lin C, Ho Lin Y, Supriyatna S, Wei Teng C. 1995. Protective and Therapeutic effects of 
Curcuma Xanthorrhiza on hepatotoxin-Induced Liver Damage, The American Journal of Chinese Medicine, 23(03:04).

Galicia Jorge, Ramirez LA, Suarez A, Crespo F, Gomez A, Soto Samuel, Ovando A, Nunez Emmanuel.2013. Vasorelaxant activity of extracts obtained from Apium graveolens: possible source for vasorelaxant molecules isolation with potential antihypertensive effect, Acian Pacific Journal of Tropical Biomedicine, 3(10): 776-9.

Intharacton T, Srisawat R. 2013. Antihypertensive Effects of Centella asiatica Extract, International Conference on Food and Agricultural Sciences, 55, IACISIT Press, Singapore

Katno. 2008. Tingkat Manfaat Keamanan dan Efektivitas Tanaman Obat dan Obat Tradisional, Balai Besar Penelitian dan Pengembangan Tanaman Obat dan Obat Tradisional, Balitbangkes Depkes RI.

Kementerian Kesehatan RI, 2007, Peraturan Menteri Kesehatan Nomor1109/Menkes/Per/IX/2007 tentang Penyelenggaraan Pengobatan Komplementer Alternatif di Fasilitas Pelayanan Kesehatan, Jakarta.

Kementerian Kesehatan RI, 2010 Peraturan Menteri Kesehatan Republik Indonesia Nomor 003/MENKES/PER/2010 Tentang Saintifikasi Jamu dalam Penelitian Berbasis Pelayanan Kesehatan, Jakarta.

Li-ming $\mathrm{C}$, Li Tian, Yong Li, Chunsheng L, Li-ya W. 2010. Antihypertensive Effect of Roots of
Apium graveolens Extract in Renal Hipertensive Rats, Chinese Journal of Experimental Traditional Medical Formulae. 11.

Matsubara T, Bohgaki T, Watarai M, Suzuki H, Ohashi K, Shibuya H. 1999. Antihypertensive actions of methylripari ochromene a from Orthosiphon aristatus, an Indonesian Traditional Medicinal Plant, Journal Biol Pharm Bull, 22(10):1083-8.

Mukti, A. G. 2000. Evaluasi Ekonomi dalam Intervensi Klinik dan Kesehatan Masyarakat, Yogyakarta

Siska, Armenia, Arifin H. 2011. Akar Seledri (Apium graveolens L) sebagai Obat Antihipertensi: Efektivitas Fraksi Etanol Air dan Etil asetat pada Tikus Putih Jantan Hipertensi, Jurnal Bahan Alam Indonesia, 7(6).

Supriyatna, Moelyono MW, Iskandar Y, Febriyanti RM, 2013, Mengenal Obat Herbal Pemahaman Obat Herbal Untuk Fitoterapi, Unpad Press, Bandung.

Ying Lee C, Hang Peng W, Yuan Cheng $\mathrm{H}$, Na Chen F, Tsung Lai M, Hui Chiu T. 2006. Hepatoprotective Effect of Phyllanthus in Taiwan on Acute Liver, The American Journal of Chinese Medicine, 34(03).

Zalizar L. 2013. Flavonoid of Phyllanthus niruri as immunodulators A Prospect to Animal Disease Control, ARPN Journal of Science and Technology. $3(5)$. 